\title{
Social Capital and Healthy Urbanization in a Globalized World
}

Pat Pridmore, Liz Thomas, Kirsten Havemann, Jaime Sapag, and Lisa Wood

\begin{abstract}
This paper critically reviews the extent in which social capital can be a resource to promote health equity in urban contexts. It analyzes the concept of social capital and reviews evidence to link social capital to health outcomes and health equity, drawing on evidence from epidemiological studies and descriptive case studies from both developed and developing countries. The findings show that in certain environments social capital can be a key factor influencing health outcomes of technical interventions. Social capital can generate both the conditions necessary for mutual support and care and the mechanisms required for communities and groups to exert effective pressure to influence policy. The link between social capital and health is shown to operate through different pathways at different societal levels, but initiatives to strengthen social capital for health need to be part of a broader, holistic, social development process that also addresses upstream structural determinants of health. A clearer understanding is also needed of the complexity and dynamics of the social processes involved and their contribution to health equity and better health. The paper concludes with recommendations for policy and programming and identifies ten key elements needed to build social capital.
\end{abstract}

KEYWORDS Health, Health equity social determinants, Social capital, Urbanization.

\section{INTRODUCTION}

There is increasing evidence that health behavior and health care delivery are influenced by a broad range of systemic and social factors, such as social capital, ${ }^{1}$ and not only biomedical factors. This has led to calls for a radical rethinking of health planning ${ }^{2,3}$ and to the need to understand how social capital may translate

Pridmore is with the Institute of Education, University of London, 20 Bedford Way, London, WC1H OAL, England; Thomas is with the University of Witwatersrand, Johannesburg, South Africa; Havemann is with the Centre for Health Development, World Health Organization, Kobe, Japan; Sapag is with the Universidad Catholica de Chile, Santiago, Chile; Wood is with the University of Western Australia, Perth, Australia.

Correspondence: Pat Pridmore, Institute of Education, University of London, 20 Bedford Way, London, WC1H OAL, England. (E-mail: p.pridmore@ioe.ac.uk) 
into better health outcomes and health equity. ${ }^{*}$ The purpose of this paper is therefore to examine social capital theory while viewing it as one subset of the broader social processes and social context that impact health. These broader social processes include the overlapping but distinct concepts of social cohesion, empowerment, and participation. Social capital/social cohesion needs to be based on true participation, which requires empowerment through redistribution of power to increase community influence over decision making and policy development concerning their well-being and quality of life.

Despite a wealth of literature in the political sciences ${ }^{4}$ and in sociology ${ }^{5}$ and to a lesser extent in health, there is still a lack of consensus on what social capital is. For the purpose of this paper social capital is defined as "the stock of active connections among people (including the trust, mutual understanding, and shared values and behaviors) that binds members of human networks and communities and that also empowers them to make cooperative action and participation possible." ${ }^{6}$ A distinction is also made between the cognitive and structural elements of social capital and horizontal and vertical dimensions (using the typology shown in Figure 1). Within this typology, linking social capital is specifically related to the processes of empowerment mentioned above that influence the structural determinants of health while bridging and bonding social capital relate to psychosocial processes involving interpersonal trust and social support that are related to the intermediary determinants.

It is also important to recognize that social capital is not a solely Western concept but one that has been taken up and conceptualized at the local level around the world. There is an African proverb saying "Sticks in bundles are stronger," which describes how social capital is perceived among many ethnic groups on the African continent. Experience from intersectoral work in Kenya has shown that social capital can be a precursor for successful implementation of participatory approaches in health and nutrition, and it is therefore important to be able to describe and assess the characteristics of social capital in a community. Communities with high levels of social capital were characterized by being ethnically more homogenous, having strong leaders (concerned with the welfare of the whole community), high levels of trust and a sense of reciprocity, and mutual support leading to wide participation, building on strong social networks. The following quotation describes how social capital has changed in a district in Kenya:

Previously you would see a man on a safari and he just carried a stick, and the wife carried a load on her head, a child on her back and held another child in her hand. But today, with the building of social unity you would find the men carrying a child on the shoulder and walk with the wife. They have understood the importance of trust and sharing the life skills and duties in the community. (District health officer)

The experiences from Kenya also showed that communities with low social cohesion were characterized by having many different ethic groups with "gatekeepers" who controlled the flow of information leading to distrust and mismanagement of resources and eventually to poor health and nutrition outcomes.

\footnotetext{
"Health equity is "the absence of systematic disparities in health or in the social determinants of health between groups with different levels of underlying social advantage/disadvantage-that is, wealth, power, or prestige."
} 

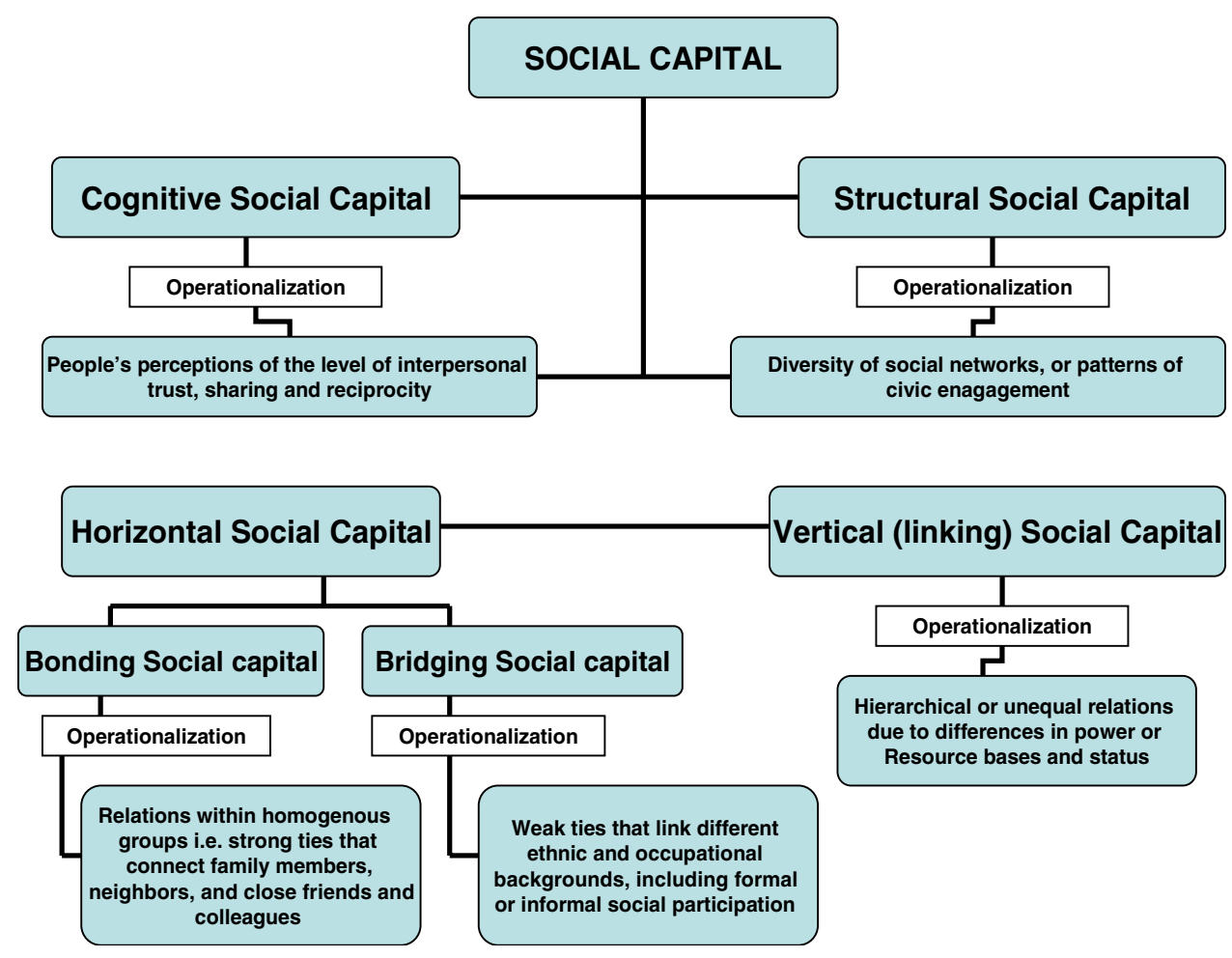

FIGURE 1. Link between cognitive and structural social capital (adapted from 7).

There were underlying conflicts in these communities, both within and between households and between community members and their leaders, linked to lack of reciprocity, weak social networks, and low levels of participation. Leaders were often greedy and jealous and sought to enrich themselves through representing their community. ${ }^{30}$

The analysis presented in this paper is informed by secondary data from published and unpublished sources and has been organized into the four levels at which social capital may operate and at which health development planning takes place: (1) micro(individual/family), (2) meso(neighborhood), (3) city, and (4) macro(national/global). At the microlevel entry points are through individuals and vulnerable people to strengthen bonding/cognitive social capital involving interpersonal trust and social support. At the mesolevel entry points are through vulnerable communities and groups such as refugees, women, and children to strengthen bridging/linking social capital involving trust, networks, membership, and participation. At the macrolevel the entry point is through policy to identify key approaches, allocation of resources, targeted strategies to strengthen bridging/ linking, and vertical social capital to build components such as trust, values, norms, ways of doing things, and social movements.

The analysis has also been developed in relation to the conditions needed for an enabling environment for social capital to impact on health equity. These conditions are (1) the legal and regulatory framework enabled by the market, (2) the political and governance context enabled by the state, (3) the sociocultural characteristics enabled by the state, and (4) the economic conditions. Each of these conditions 
operates through the capacity of different actors and is facilitated by social capital/ cohesion as well as participation, empowerment, inclusion, and accountability.

This paper is organized into three main sections. First, it reviews evidence to link social capital to health outcomes and health equity, taking into consideration the many difficulties in measuring and assessing social capital. Second, it describes possible pathways and actions through which social capital may operate at different societal levels. Third, it draws out the implications for social sector and health policy and practice, identifying 10 key elements needed to build social capital in urban settings.

\section{EVIDENCE TO LINK SOCIAL CAPITAL TO HEALTH EQUITY}

In evaluating the evidence, methodological limitations and challenges need to be taken into consideration. Limitations include the common use of a cross-sectional design, which cannot provide evidence of causality, and the use of limited proxy measures extracted from secondary data sets because social capital cannot be measured directly. ${ }^{8}$ Very few published social capital instruments have been subjected to construct validity using factor analysis, or to reliability testing, ${ }^{9}$ and most studies measure social capital at the individual level and then discuss what happens at the community level. There is a huge variation in the measures used to assess social capital with overall measures typically being represented by an aggregation of measures of particular social capital domains. " In some countries government agencies have carried out national surveys monitoring social capital ${ }^{10}$ and there have been some cross-national efforts to progress the measurement and facilitation of it. ${ }^{11}$ Elements of social capital are also sometimes present in existing indicators used to measure societal conditions or health/wellbeing.

Challenges to assessing social capital include the need to distinguish findings based on psychological measures from those related to social conditions and to disaggregate data to separate population effects from individual effects using multilevel analysis. There is a need to disentangle the effect of social capital from that of other factors and to capture all the different elements and dimensions of social capital. There is also a need to focus on the mechanisms that create vertical, and not just horizontal bonds, between groups at different societal levels (because these bridging and linking connections contribute to empowerment and greater health equity). The contextual variability of social capital also renders its core features more difficult to operationalize ${ }^{12}$ with understandings of social capital varying widely between countries and between different settings and population segments. This variation limits the generalizability of measures and findings ${ }^{13}$ and requires outcome measures to be adapted to local contexts.

The Evidence Base Despite the limitations and challenges described above, the current evidence base yields a good number of studies from both more and less

\footnotetext{
*The Social Capital Gateway (http://www.socialcapitalgateway.org) and the World Bank's social capital website http://www.worldbank.org/social capital) provide links to many social capital measures that have evolved in more and less developed countries. The table given in the Appendix shows a range of methods used to assess social capital.
} 
developed countries using a wide range of research designs that provide reasonable evidence for a link between higher social capital and better health conditions (reflected in a higher life expectancy and lower rates of mortality and morbidity), and evidence that this link persists when controlled for sociodemographic and socioeconomic variables. ${ }^{14,15}$ Moreover, higher social capital has frequently been associated with higher self-rated levels of health in poor populations. ${ }^{16,17}$ The fact that some studies have not shown any clear relationship between social capital and health ${ }^{18}$ may be partly explained by difficulties in assessing and comparing social capital in different contexts and by variation in the assessment methods used. It is evident, however, that more rigorous studies are needed to further clarify the complex relationship between social capital and health and to try to establish a causal link.

There is good evidence that inequity caused by disparities in income distribution can erode trust and diminish social capital. ${ }^{19,20}$ This would suggest a need to address the more macrolevel social and economic processes that influence health. A stronger focus on the role of public services and social policy in generating vertical solidarity could open up new avenues for research and may also offer an explanation for some of the current conflicting evidence. ${ }^{21}$

Evidence at the Microlevel Researchers have evaluated the relationship between a number of social capital indicators and self-rated health with varying results. One study found little evidence for compositional effects on health ${ }^{22}$ whereas another study found an association between the number of friends, level of mistrust, group membership, and self-rated health after controlling for a large number of other health-related variables. ${ }^{23}$ Other studies have found that social capital variables account for a significant amount of physical and emotional health at the individual level and that those reporting high levels of trust have better self-rated health status and greater life satisfaction. ${ }^{24,25}$

At the microlevel there is disagreement about whether the benefits of social capital are associated with individuals and their relationships or are a collective attribute of communities. One study using data from the European Social Survey in 22 countries found that social capital does not uniformly benefit individuals living in the same community or society. ${ }^{26}$ But other cross-national studies indicate that individual-level analysis of social capital along with macrolevel determinants is important for understanding health, especially of the elderly. ${ }^{27}$ Other studies have found that cognitive social capital is positively associated with child nutritional status $^{28}$ and mental health. ${ }^{29}$ A case study from South Africa suggested that a targeted microfinance intervention combined with a participatory learning and action curriculum can reduce women's vulnerability through increased social capital and reduce incidence of physical and/or sexual abuse. ${ }^{30}$

Evidence at the Mesolevel There is good evidence that neighborhood characteristics influence health. A study in the USA found neighborhood social capital was associated with lower death rates, after adjustment for material deprivation ${ }^{31}$ and a study in the UK found a link between the structural characteristics of neighborhoods and individual health outcomes. ${ }^{32}$ Another study has shown that trust is a crucial factor for improving health outcomes of deprived populations and ensuring access to resources and infrastructure. ${ }^{33}$ A case study from Kenya found that an intervention to build social cohesion, improve child nutrition and health outcomes was successful in an ethnically homogenous district but not in a district that had 
many ethic groups and lacked social cohesion. ${ }^{30}$ A case study from rural Mexico and Guatemala also identified social capital as important for poor communities to make the most of their assets, improve their living conditions, and combat social exclusion. But it concluded that for sustainability, government should play a key role in creating institutions to facilitate the participation of excluded groups and to create spaces of dialog and agreement between social actors. ${ }^{30}$

Evidence at the City Level Studies looking at intraurban health differences tend to explore associations between environmental conditions and health outcomes and some data sets include social capital variables measured at community level. ${ }^{34} \mathrm{~A}$ case study from India demonstrated that advocacy of federations can lead to mobilization of large groups of people across a city and increase cohesion of informal community networks in slum areas. ${ }^{30}$ A case study from Western Australia demonstrated that in building social capital and healthy communities, processes are as important as outcomes. This study highlighted the need for a range of program evaluation measures. ${ }^{30}$

Evidence at the Macrolevel Putnam's ${ }^{35}$ work in Italy considered the role of social capital in regional economic performance and other early social capital and health studies assessed the relationship between dimensions of regional social capital with specific health outcomes and trust. ${ }^{36}$ Whereas studies exploring the association between social capital and health at this level remain broad, social action (a dimension of social capital) can play a powerful role in helping to address health equity. By contrast, a study in Colombia, South America, explored the relationship between social capital, violent deaths, and the accumulated occurrence of cancer deaths. The findings showed a positive direct relationship among "perverse" social capital and violence and between violent deaths and all types of cancer (except breast cancer and lung cancer among men). ${ }^{30}$

Downsides of Social Capital Risks of social capital include the possibility that strong ties between some community members may exclude others and also compromise the development of successful initiatives for members that do not fit the norm. There is also the risk that a focus on social capital may lead to passivity in search of integral and structural responses for development problems, inequities, and health. ${ }^{37,38}$

\section{PATHWAYS AND ACTIONS THROUGH WHICH SOCIAL CAPITAL MAY OPERATE}

Having briefly reviewed the evidence base this paper will now consider how increased social capital may be translated into better health. This task is challenged by social capital's diffusive nature and relative infancy compared with other community-oriented concepts and it is therefore useful to draw upon related bodies of theory, including governance, empowerment, sustainable urban development, participation, civil society, and collective efficacy. Key actors at all levels include politicians and government officials.

At the Microlevel Cognitive, bonding social capital operates through strengthening social support for individuals and vulnerable households and there is epidemiological evidence to link it to positive mental and overall health outcomes. Individuals 
and households that are healthier are better able to cope and participate in community and economic activities and thereby play a role in contributing to health equity. This is known as the "spiral up." There is also evidence to link violent societies with poor mental heath contributing to a downward spiral, and for the poor health of household members impacting on the mental health of carers and their withdrawal from participation in community activities. ${ }^{30}$

At the Meso- and City Level Bridging/linking, vertical social capital operates here. Capacity building can lead to neighborhood committees and community-based organizations (CBOs) participating with local government in proactively addressing local needs for basic services and health care. Social capital interventions to empower community groups to increase control of their lives and challenge local injustice could influence rules, norms, and values to become more propoor, provided that the poor are able to develop connections and links or mechanisms to have their voices heard. These city-wide interventions could lead to changes in city policy and practice as well as impact positively on the more just allocation of resources between communities and sectors. A city-wide propoor policy may provide the enabling environment for targeted interventions to address the living conditions of especially vulnerable groups. This can address intraurban health differentials and thus health equity.

At the Macrolevel Bridging/linking, vertical social capital again operates here. A key pathway is through the advocacy of federations of CBOs and NGOs and other civil society groups to mobilize community groups for a more just and sustainable world through change in policy and access to infrastructure and resources. ${ }^{39}$ The link between social capital and health may result in a further spiraling effect between levels, upward to greater health and health equity or downward to poorer health and greater inequity. Figure 2 shows how the different types of social capital are related to different levels and linked to participation and empowerment.

Actioning Social Capital Within current approaches to health, social determinants are often "defined" in relation to their place in the "stream" of health causation and intervention. Vertical social capital, for example, has a more upstream orientation, influencing relationships between different levels of society and across power or authority gradients. ${ }^{40}$ A community may be rich in networks and connections, but poor in the assets and resources that enable people to escape from poverty. Bonding social capital by contrast aligns strongly with the psychosocial determinants of health reflected in midstream orientations. Bridging social capital seems pertinent at both downstream and midstream points, encapsulating links and connections to people and systems of support outside one's own circle. Distinguishing between types of social capital helps identify appropriate interventions and entry points.

\section{IMPLICATIONS FOR SOCIAL SECTOR AND HEALTH POLICY AND PRACTICE IN URBAN SETTINGS}

This section draws on the evidence base and the possible pathways described to identify implications for policy and practice. Moving forward will require challenging the outdated thinking that underlies the use of the linear approach to health development planning ${ }^{41}$ and the way in which some planners still ignore the 


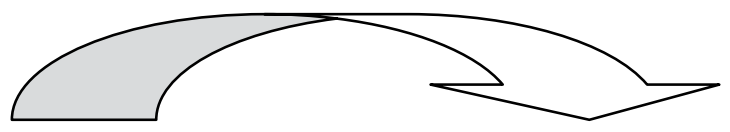

Empowerment
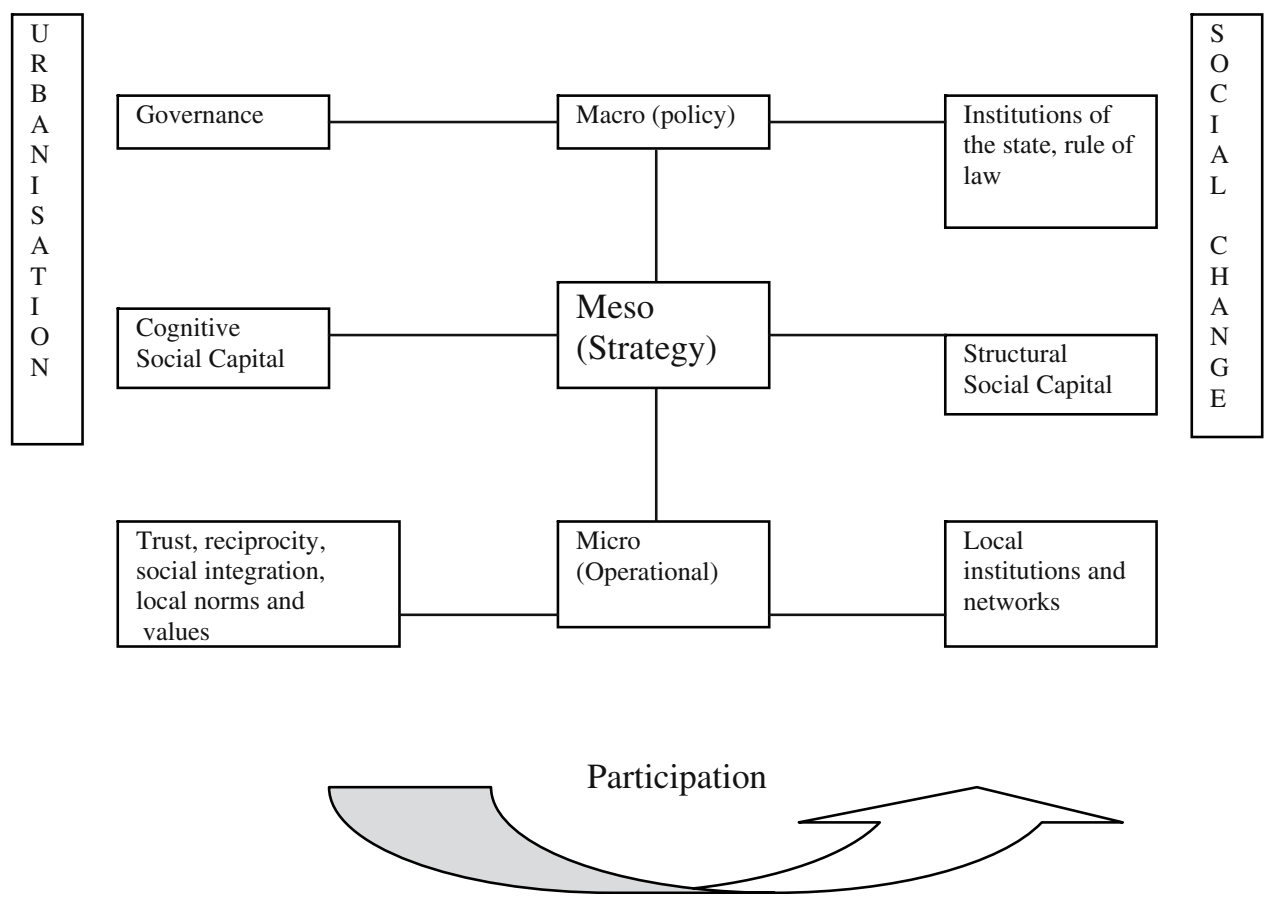

FIGURE 2. Types of social capital related to different levels and linked to participation and empowerment.

significance of social processes. Such planners often fail to understand that different types of social capital need different institutional settings and dimensions embedded in social and political contexts that preclude the possibility of purely administrative or economic solutions. The challenge is therefore not only to help government create optimal policies, but also to tease out types of reforms that are socially acceptable and institutionally feasible to develop both policies and interventions that improve life/health/infrastructure for those in poor areas.

Moving Forward at the Microlevel Social cohesion is important for mobilizing efforts to rebuild local organizations that are led by collaborators who live and work in the community. Careful selection and monitoring is needed, however, to ensure that these collaborators have the interests of the whole community at heart. It is also important that microlevel interventions promote the needs of vulnerable groups without undermining their coping strategies. The case studies presented earlier have also shown the importance of using iterative and multidisciplinary approaches and finding an entry point that reflects the "felt need" of individuals.

Moving Forward at the Mesolevel At this level politicians can benefit from supporting local rather than system and political solutions to ill health. In the case 
of child health these local solutions have been shown to require attention to building social capital, especially in poor areas. ${ }^{42}$ Health workers also have an important role to play in supporting the development of social capital for child health as part of a broad based multiagency team, but such a team can only be created with support from health systems planners and politicians as well as planners in other social sectors.

Moving Forward at the City Level Poor urban settlements require special interventions to address social exclusion, disruption of social networks and trust, insecurity and violence, and high mortality and morbidity. Governments and donors frequently support partnering of informal dwellers to create intermediary organizations and networks that can represent the weakest stakeholders through community participation and empowerment building approaches. Here, there is a need to build on already existing successful programs and bring these experiences to the attention of public policy makers. In this process the " $5 \mathrm{~W}$ 's" (who, why, when, where, how, and who) can guide equitable planning, implementation, monitoring, and evaluation of health interventions.

Moving Forward at the Macrolevel Efforts to strengthen social capital need to be included in broader health and social sector programs using a social educational approach. This involves sharing knowledge and skills and intervening in sectors considered relevant for improving health in urban settings especially for vulnerable groups. But flexibility is needed in the knowledge-building process and specificity in decision making. Local forms of social capital/cohesion can be developed from the state level and local groups and networks can be created to respond to weak and dysfunctional state structures. Building micro- and mesolevel social cohesion can also help the functioning of the state. ${ }^{43}$

Integration of SWAp and PRSPs Given current recognition that the sector-wide approach (SWAp) has introduced serious problems, ${ }^{44}$ we consider that social capital as a subset of the broader social and contextual context has a crucial role to play in the interface between and within sector reforms and in linking sector

TABLE 1 Checklist of six assumptions necessary for realistic policy intervention for social capital

Checklist

1. We know what the current conditions are including the role of norms.

2. We know what the current health and social sector trends are and where we are likely to end up after a particular period of time if these trends persist, i.e., our likely end conditions.

3. We are able to determine a preferred alternative outcome, or our desired outcome.

4. We can formulate health and social sector policies (based on past experience, intuition, and formal models of social capital and cohesion) that will change the current trends and help us reach our desired outcome.

5. We have the capacity (skills, resources, consensus, etc.) to implement these health policies in a sufficiently consistent manner so as to reach our desired outcome.

6. We have the monitoring capacity in place to inform us if we are going off the desired path, thus, how we need to modify our health and social sector policies, and when we actually reach our desired outcome. 
reforms to poverty reduction strategies. However, this linking requires health policy makers, international communities, and their technical representatives to be able and willing to work intersectorally and share information, ideas, and resources. We suggest that social capital should be included in the SWAp with benchmark indicators of development, linking health sector reforms with poverty reduction strategy papers (PRSPs) and service provision performed. It would then combine top-down with bottom-up approaches. Linking SWAps to PRSPs could create political space for social capital. Participative decentralization is necessary to promote social capital and no standard model is suitable for all regional and local contexts worldwide. However, there is a universal need to back participatory development with sufficient funding and take account of power and politics. Decentralization and participation are not just about reducing bureaucracy and making it more efficient, they are a matter of power sharing and local autonomy and sustainable development is better achieved where strong local communitarian organization is in place. ${ }^{45}$

Assessment as Part of Operationalizing Social Capital Given the high costs of data gathering for health and social policy programming, minimal systems are often put in place to ensure donor requirements for financial probity with health effectiveness

TABLE 2 Ten actions needed to build social capital as part of a social development/social justice process

Actions

1. Assessing the context and asking the right questions: The choice of questions is influenced by the expected size and direction of health impacts, the prominence of the issue in the government's policy agenda, and the timing and urgency of the underlying health policy or strategy.

2. Identifying stakeholders: Stakeholder analysis identifies the people, groups, and organizations that are important to consider when looking at the health impacts.

3. Developing the capacity of stakeholders to take action and build social capital and cohesion: The expected policy change can only take place if sufficient knowledge, skills and resources are in place.

4. Assessing institutions and creating opportunity to ensure intersectoral collaboration: Institutions determine the framework in which policy reforms may affect stakeholders in government, private sector, and civil society, and are the main arenas in which stakeholders interact with one another.

5. Strengthening the demand side of governance: Assessing and ensuring people's participation from the organizational and legal aspect, including a concern with ensuring access to data.

6. Strengthening institutions role, function, and structure: Involves organizing and creating critical links between the policy objectives, policy actions, and their impacts on key stakeholder groups within the health and other sectors at various levels.

7. Mobilizing resources: To the extent that they are necessary for social change. This may require better redistribution of resources.

8. Advocate for up-scaling and change: Policy and advocacy to relevant stakeholders at different levels

9. Monitoring and evaluating impacts: Provides an opportunity to set up at an early stage systems for monitoring,

10. Identifying the appropriate level and type of intervention: Individual, neighborhood, city, etc. 
being judged on a range of crude proxy indicators such as facility utilization and simplistic measures of client satisfaction. Greater use of rapid assessment procedures, combined with visual participatory data generated and analyzed by the users to ensure congruence and cohesion building, could be a cost-effective way to improve data gathering. We consider that the six assumptions shown in Table 1 can help planners include social capital considerations in their needs assessment. However, there is a need to have some degree of confidence that the essentials of these assumptions can be met.

Key Elements Needed to Build Social Capital Based on the findings and discussion in this article we have developed a final checklist of 10 key elements that we consider to be needed for building social capital as part of a social development/ justice process. These elements are listed in Table 2.

\section{CONCLUSION}

To promote the importance of social capital in health development planning we need to be able to measure, monitor, and advocate for it and collectively reallocate resources. This will call for a retooling and rebalancing of the public health workforce so that the individualistic biomedical and economic view of the world is complemented with a collective, social science focus on community and social structures. There is a key role here for health workers in documenting health outcomes and disseminating findings to increase recognition of the value of social sector interventions, but resistance from within the health sector will need to be overcome. Research is more likely to contribute to policy if it fits well with the political context; the evidence is credible and researchers and policy makers share common networks and trust each other. ${ }^{46}$ To maximize the chances of success, strong common networks will therefore be needed to identify policy reform champions who can overcome resistance and enable the right proposals to be put to the right people at the right time.

We consider that the $10 \mathrm{key}$ elements we have identified as important in building social capital provide a useful practical guide for policy development and practice. These elements can help to realize the contribution that social capital can make toward healthy urbanization in a globalized world.

\section{ACKNOWLEDGEMENTS}

This paper arose from the contributions of many people from within and outside the health sector and continents. The process of writing the paper has been a participatory learning experience in itself and has included contribution from field practitioners from civil society, private and public sectors based on many years of experiences. We owe much to these people and to the institutions they represent but a special thank you should go to Marwan Khawaja from the American University of Beirut, Richard Bradford and Makie Kawabaki from the WHO Kobe Centre for Health Development, Japan, Ms. Sujata Khandekar from CORO, Mumbai, Mr. Paul Pronyk, Rural AIDSdevelopment Action Research Programme, School of Public Health, University of Witwatersrand, South Africa. 


\section{APPENDIX}

TABLE 3 Examples of measures that have been used to assess social capital at the various levels

\begin{tabular}{|c|c|c|}
\hline Level & Qualitative or quantitative survey data sources & Objective or secondary data sources \\
\hline \multirow[t]{3}{*}{ Individual } & $\begin{array}{l}\text { Access to employment opportunities through } \\
\text { informal contacts. Willingness to help others } \\
\text { and examples of favors provided }\end{array}$ & Membership of clubs and groups \\
\hline & $\begin{array}{l}\text { Presence of close relatives or friends nearby. } \\
\text { Trust in others generally and in immediate } \\
\text { relational contexts. Trust in others generally } \\
\text { and in immediate relational contexts }\end{array}$ & $\begin{array}{l}\text { Evidence of exclusion of particular } \\
\text { population groups from club } \\
\text { or group membership }\end{array}$ \\
\hline & & $\begin{array}{l}\text { Availability of perceived and actual } \\
\text { support } \\
\text { (Instrumental, emotional and } \\
\text { informational) }\end{array}$ \\
\hline \multirow[t]{4}{*}{ Neighborhood } & $\begin{array}{l}\text { Residents trust in-service providers (e.g., doctor, } \\
\text { banks, teachers) }\end{array}$ & $\begin{array}{l}\text { Types and "density" of cooperative } \\
\text { groups (e.g., credit or produce } \\
\text { coops) }\end{array}$ \\
\hline & $\begin{array}{l}\text { Attitudes toward and participation in local } \\
\text { governance }\end{array}$ & $\begin{array}{l}\text { Examples of collective action on a } \\
\text { neighborhood issue }\end{array}$ \\
\hline & $\begin{array}{l}\text { Perceptions of trust and helpfulness of others } \\
\text { at neighborhood level Intratrust between } \\
\text { group members as well as group trust } \\
\text { of others }\end{array}$ & $\begin{array}{l}\text { Membership rates and decision- } \\
\text { making processes in community } \\
\text { organizations Uptake or diffusion } \\
\text { of new ideas (e.g., farming } \\
\text { practices and immunization }\end{array}$ \\
\hline & $\begin{array}{l}\text { Perceptions of decision-making processes, } \\
\text { fairness, tolerance of diversity }\end{array}$ & $\begin{array}{l}\text { Participation in local elections } \\
\text { and decision making }\end{array}$ \\
\hline \multirow[t]{8}{*}{ City } & $\begin{array}{l}\text { Awareness of community networks, groups, } \\
\text { support services }\end{array}$ & $\begin{array}{l}\text { Presence of and access to support } \\
\text { systems, e.g., welfare, healthcare, } \\
\text { education, and housing assistance }\end{array}$ \\
\hline & Trust in city governance systems & $\begin{array}{l}\text { Policies/laws that support or erode } \\
\text { social capital }\end{array}$ \\
\hline & $\begin{array}{l}\text { Adequacy of services and level and quality } \\
\text { of services and built environment }\end{array}$ & $\begin{array}{l}\text { Mapping of relationships and networks } \\
\text { that exist among formal and } \\
\text { informal institutions }\end{array}$ \\
\hline & Voting patterns for civic leaders & $\begin{array}{l}\text { Access to government or NGO funds for } \\
\text { social or infrastructure projects } \\
\text { relative to other cities }\end{array}$ \\
\hline & Homogeneity/heterogeneity of neighborhoods & \\
\hline & $\begin{array}{l}\text { Number and range of active civil society } \\
\text { groups and projects }\end{array}$ & \\
\hline & $\begin{array}{l}\text { Case studies and outcomes of cooperatives } \\
\text { and civil society initiatives (e.g., group } \\
\text { lending }\end{array}$ & \\
\hline & $\begin{array}{l}\text { Aggregated individual responses to sense of } \\
\text { empowerment and input to decision } \\
\text { making }\end{array}$ & \\
\hline \multirow[t]{2}{*}{ Regional/national } & $\begin{array}{l}\text { Case studies of civil society groups and } \\
\text { changes and capacity building brought } \\
\text { about through these }\end{array}$ & Voting participation rates \\
\hline & $\begin{array}{l}\text { Examples of collective action on an issue } \\
\text { and outcomes of this }\end{array}$ & $\begin{array}{l}\text { Monitoring number, range, and outcomes } \\
\text { associated with of active civil society } \\
\text { groups and projects }\end{array}$ \\
\hline
\end{tabular}




\section{REFERENCES}

1. Wilkinson R, Marmot M, eds. Social Determinants of Health: the Solid Facts. Copenhagen: WHO; 2003.

2. Havemann K, Pridmore P. Social Cohesion: The Missing Link to Better Health and Nutrition in a Globalized World. New Frontiers of Social Policy: Development in a Globalized World, 12-15 December, 2005. Arusha, Tanzania: The World Bank; 2005.

3. World Bank. Improving Health Care for the Poor. Washington, DC: World Bank; 1999.

4. Putnam RD. Bowling alone: America's Declining Social Capital. J. Democr. 1995;1 (January):65-78.

5. Coleman J. Social capital in the creation of human capital. Am J Sociol. 1988;94(Suppl):S95-S120.

6. Cohen D, Prusak L. In Good Company. How Social Capital Makes Organizations Work. Boston, MA: Harvard Business School Press; 2001.

7. Islam KM, Merlo J, Kawachi I, Lindström M, Gerdtham U. Social capital and health: Does egalitarianism matter? A literature review. International Journal for Equity in Health 5; 2006.

8. Harpham T, Grant E, Thomas E. Measuring social capital within health surveys: key issues. Health Policy Plan. 2002;17:106-111.

9. Macinko J, Starfield BT. The utility of social capital in research on health determinants. Milbank Q. 2001;97(3):387-427.

10. ABS. Measuring Social Capital: Discussion Summary and Next Steps. Canberra: Australian Bureau of Statistics; 2002.

11. World Bank. What is Social Capital? Washington, DC: World Bank; 1999.

12. Harriss J. 'Missing link' or analytically missing? The concept of social capital. J Int Dev. 1997;9:919-937.

13. Pollack C. Social capital and health among the aged: comparisons between the United States and Germany. Health Place. 2004;10(4):383-391.

14. Lomas J. Social capital and health: implications for public health and epidemiology. Soc Sci Med. 1998;47(9):1181-1188.

15. Lochner K, Kawachi I, Brenner RT, Buka BL. Social capital and neighborhood mortality rates in Chicago. Soc Sci Med. 2003;58(8):1797-1805.

16. Kim D, Subramanian SV, Kawachi I. Bonding versus bridging social capital and their associations with self rated health: a multilevel analysis of 40 US communities. J Epidemiol Community Health. 2006;60(2):116-122.

17. Mellor J, Milyo J. State social capital and individual health status. J Health Polit Policy Law. 2005;30(6):1101-1130.

18. Lynch J, Smith GD, Hillemeier M, Shaw M, Raghunathan T, Kaplan G. Income inequality, the psychosocial environment, and health: comparisons of wealthy nations. Lancet. 2001;358:194-200.

19. Kawachi I, Kennedy BP, Lochner K, Prothrow-Stith D. Social capital, income inequality and mortality. Am J Public Health. 1997;87:1491-1498.

20. Galea S, Vlahov D. Urban health: evidence, challenges and directions. Annu Rev Public Health. 2005;26:341-365.

21. Whitehead M, Diderichsen F. Social capital and health: tip-toeing through the minefield of evidence. Lancet. 2001;358(9277):165-166.

22. Veenstra G. Social capital, SES and health: an individual-level analysis. Soc Sci Med. 2000;50(5):619-629.

23. Hyyppä MT, Maki J. Individual-level relationships between social capital and self-rated health in a bilingual community. Prev Med. 2001;32(2):148-155.

24. Rose R. How much does social capital add to individual health? A survey of Russians. Soc Sci Med. 2000;51(9):1421-1435.

25. Barefoot JKE, Maynard JC, Beckham BH, Brummett K, Hooker K, Siegler IC. Trust, health, and longevity. J. Behav Med. 1998;21(6):517-526. 
26. Poortinga W. Social capital: an individual or collective resource for health? Soc Sci Med. 200615 July 2005;62:292-302.

27. Pollack C, von dem Knesebeck O. Social capital and health among the aged: comparisons between the United States and Germany. Health Place. 2004;10(4):383-391.

28. De Silva M, Harpham T. Maternal social capital and child nutritional status in four developing countries. Health Place. 2007;13(2):341-355.

29. Thomas E. Social capital and mental health of women living in informal settlements of Durban, South Africa and Lusaka, Zambia. In: McKenzie K, Harpham T, eds. Social Capital and Mental Health. London: Jessica Kingsely; 2006.

30. Pridmore P, Thomas L, Havemann K, Sapag J, Wood L. Social Capital and healthy urbanization in a globalized world. Thematic Paper. Kolbe: WHO, Centre for Health Development; 2006.

31. Lochner KAK, Brenner I, Buka RT, Uka BL. Social capital and neighbourhood mortality rates in Chicago. Soc Sci Med. 2003;58:1797-1805.

32. McCulloch A. An examination of social capital and social disorganisation in neighbourhoods in the British household panel study. Soc Sci Med. 2003;56(7):1425-1438.

33. Chavez R, Kemp L, Harris E. The social capital: health relationship in two disadvantaged neighbourhoods. J Health Serv Res Policy. 2004; 9 (October):29-34.

34. Stephens CM, Akerman S, Avle S, et al. Urban equity and urban health: using existing data to understand inequalities in health and environment in Accra, Ghana and São Paulo. Environ Urban. 1997;9(1):181-202.

35. Putnam R. Bowling Alone: the Collapse and Revival of American Community. Cambridge, Massachusetts: Harvard University; 2000.

36. Kawachi I, Kennedy BP, Lochner K, Prothrow-Stith D. Social capital, income inequality and mortality. Am J Public Health. 1997;87:1491-1498.

37. Pearce N. Traditional epidemiology, modern epidemiology, and public health. Am J Public Health. 1996;86:678-683.

38. Mckinlay J. The promotion of health through planned sociopolitical change: challenges for research and policy. Soc Sci Med. 1993;36:109-117.

39. Korten D. Getting to the 21st Century-Voluntary Action and the Global Agenda. West Hartford: Kumarian Press; 1990.

40. Szreter SWM. Health by association? Social capital, social theory, and the political economy of public health. Int J Epidemiol. 2004;28:650-667.

41. Cleaver F. Institutions, Agency and the Limitations of Participatory Approaches to Development. In: Cooke B, Kothari U, eds. Participation: The New Tyranny? London: Zed Books; 2001.

42. Alperstein G, Nossar V. Can the Families First Initiative contribute to reducing health inequalities? N S W Public Health Bull. 2002(13):38-41.

43. Grootaert C, van Bastelaer T, eds. The Role of Social Capital in Development. Cambridge: Cambridge University Press; 2002.

44. Pavignani E. Swamped in SWAP? Experience-inspired Remarks About Sector-wide Approaches. Maputo: Sn. Mimeo; 2001.

45. Larranaga O. Incorporating Social (Minimum) Services in the Measurement and Assessment of Poverty: Conceptual and Policy Issues with an Application to Chile. New Frontiers of Social Policy in a Globalized World. Arusha, Tanzania: World Bank; 2005.

46. Court J, Hovland IJY. Bridging Research and Policy in Development: Evidence and the Change Process. Rugby, UK: ITDG Publishing; 2005. 